\title{
Problems in the Teaching of Dance Practice in Colleges and Universities in China and Suggestions for Optimization
}

\author{
Xin Li \\ Art college of xiamen university $\quad 361005$
}

Keywords: dance teaching; teaching practice; optimization strategy

\begin{abstract}
College dance teaching needs to adopt a combination of theory and practice. During the process of dance learning, undergraduates continue to practice the stage to further master the skills of dance movement to improve their professional skills. This is the teaching of dance in colleges and universities. Effective methods, this article based on the current status of college dance practice and the problems faced in teaching analysis, through the importance of teaching practice and put forward optimization and improvement measures.
\end{abstract}

\section{Introduction}

For specific subjects such as arts, the application of practical teaching may be more meaningful than theoretical teaching. The Ministry of Education of the People's Republic of China issued the "National Medium and Long-term Education Reform and Development Plan Outline (2010-2020)" clearly pointing out that it must be strengthened in the field of higher education. Practice teaching link [1]. The cultivation of practical ability has become one of the three major capabilities that high-quality talent must possess. Dance is a way of expressing art with body movements. Therefore, it is particularly necessary to focus on practical aspects. In China's current university teaching, there is still a certain degree of certainty. The degree of practical teaching defects, which has a certain impact on improving the quality of dance teaching in colleges and universities.

\section{Problems in the Teaching of Dancing Practice in Colleges and Universities}

\subsection{Students Lack of Interest and Confidence in Learning}

The teaching process of any subject theory is usually boring, and the interest is to learn the best teacher. However, in the traditional college dance teaching mode, the teacher teaches professional knowledge in the classroom and the student passively learns. Therefore, the students lack the initiative to learn. Introducing and strengthening practice links between teaching can allow students to demonstrate their own learning results while demonstrating their own expertise while allowing students to truly feel the importance of their own teaching relationships, thus further stimulating learning initiative [2 ]. As a group of teenagers, college students are characterized by their liveliness, goodwill, and willingness to express themselves. Therefore, through the introduction of practical methods in teaching, students are provided with a stage to show themselves, thereby further stimulating students' interest in learning and allowing students to practice in the stage . By presenting themselves in stage performances, the recognition and support of the exhibition process by others will greatly encourage students, and the confidence and courage of the dance performance will be greatly enhanced, and the satisfaction with successful performances will be appreciated.

\subsection{The practical application platform does not effectively build up students' creative abilities}

The strengthening and application of practice teaching in dance teaching is the need of the development of the times. At present, the training of dance professionals in Chinese universities lacks talents that are not only professional skills, but also possess innovative thinking skills and practical application professional skills, which also limits the dance art of our country. The requirements of the undertakings for training dance professionals in colleges and universities can therefore be used to build a practical platform for the training of talents with comprehensive 
qualities, so that students can improve their independent thinking through practice, and deepen their understanding of dance art through the accumulation of stage experience. It can be based on their own unique experience to present their own insights and even to innovate and cultivate their own original creative ability of dance creation. By maximizing students' autonomy in the teaching of dance practice and allowing students to create and arrange programs for dance practice, students' creative abilities and awareness have been greatly developed, and the original layout of dance programs can be independently performed. Students can use the experience and resources accumulated in practice in the creation of dance repertoire, and provide advice and suggestions on the creation of props, actors, composition, and choreography through hiring excellent choreographer's guidance and transmission of artistic creation experience and ideas. It can greatly enhance the creative level of teachers and students of dance majors in colleges and universities, broaden the creative ideas, and update the creative methods, which can play a major role in improving the creative teaching ability of dance teaching in colleges and universities [3].

\subsection{Dance Theory Consolidation and Expression Skills Development Unbalanced}

After learning the dance theory in the classroom, the students still need to provide a stage for the theoretical knowledge through practice. Therefore, the practical aspects of dance teaching can provide students with the opportunity to combine theory with practice. Students can exchange ideas and promote theories through practice and performance. The combination of knowledge and practice can promote the improvement of students' dance artistic accomplishment. Students can also demonstrate the comprehensive and coordinated development of skills and knowledge through practical means, and further deepen their own understanding of theoretical knowledge.

In higher education, we have always attached importance to the implementation of the principle of "relevance of theory with practice, study with knowledge, and application of knowledge". It can be seen that only by incorporating dance knowledge and skills into the practice of digesting theoretical knowledge can we truly translate the theory into practical application skills. In the practice of dance performances, students discover their own deficiencies through mutual exchanges, further stimulate their self-motivation, enhance their motivation in learning, and further enhance their dance art and skills through the combination of theory and practice.

We found in practical teaching that some students have great input in theoretical knowledge, but in practice, they lack the ability to apply what they have learned. Therefore, actual dance skills have not been able to achieve breakthroughs. The teacher used to encourage him to participate in the stage practice in his teaching. In the process of practice, his emotions were also influenced by the artistic accomplishment. He also received a kind of influence. In the performance, he found the feeling of formative dancing and dancing, and his dance skills were quickly improved.

\section{How to Construct an Optimized Dance Practice System to Solve the Problems in Dancing Practice Teaching in Colleges and Universities}

\subsection{The establishment of teaching practice platform in colleges and universities}

Colleges and universities can set up excellent teacher teams through the establishment of dance drama research centers to promote the establishment of training grounds for college dance teaching talents, provide talent reserve and academic guidance teams for college dance education, build specialty brands for practice teaching in universities, and build dance practice teaching bases. The creation room creates a good atmosphere for college students' dance practice.

Colleges and universities should provide a broader stage for students' practice by cooperating with other art groups outside the school. This will provide a broader stage for students' practice. Under the guidance of teachers, students will be encouraged to step out of the campus and out of the classroom with the support of social art groups. The pace of practice construction should be based on continuously improving their dance skills and artistic accomplishment in practice to consolidate the teaching results. In addition, colleges and universities use a loose cooperation model to establish an off-campus practice base, which is not conducive to the use of the practice base. In the future, 
the reform should adopt a fixed cooperation model to replace the off-campus art group' $\mathrm{s}$ teachers and quality. Practical Courses Improve Students' Quality of Practice. On the other hand, the ability of teachers and students to use their own professional skills and knowledge to effectively provide solutions to the actual operation difficulties and problems of the base also needs to be improved, thus promoting the realization of a win-win situation for universities and social practice bases.

\subsection{Improve college students' practical ability training and evaluation system}

The current practice teaching model cannot guarantee that the continuity of experience limits the achievement of dance practice. Therefore, colleges and universities should establish a fixed practice ability training process to consolidate and enhance the effectiveness of teaching effects. For example, the Nanjing Dance Art Academy forms a fixed model: classroom Training-Stage performance-The training mode of dance competition actively selects outstanding students, organizes selected students to participate in various performances by various art groups, and further improves students' artistic performance.

In addition, in classroom teaching, the introduction of practice-oriented scientific research projects encourages and guides students in the development of social practice projects, and actively explores holiday seasons to enrich the creative themes while also enabling students to better comprehend the culture and practice of dance, forming a virtuous cycle of classroom theory teaching and practice.

Persist in introducing a combination of the first and second classrooms in the student evaluation system. Students are required to participate in community activities and cultural performance public services in order to improve their practical abilities. Students who have outstanding performance in the exchange practice should be encouraged to research later. The extra points encourage students to take the initiative to participate in dance training room training, and regularly evaluate the effectiveness of students' dance practice.

\subsection{Formulate a practice-oriented talent development plan}

In order to carry out dance teaching in colleges and universities, we should further increase the ratio of the proportion of time spent in practical teaching courses, construct the curriculum system of social art practice, professional practice, and public practice, and increase the proportion of credits for practical courses. In addition, the content of practical courses should be further enriched. For example, in an instructional plan proposed by a certain art college, the requirements for curriculum reform must include the addition of repertoire training, impromptu performances, and routine training. These requirements are proposed for the conversion of student works. Provide a broad space for expansion. The college curriculum has further increased the proportion of practical courses such as "Artistic Collection" and other specialized features. Art colleges emphasize the idea of three major teaching modes in the teaching of dance students: situational modeling, activity teaching, and demonstration imitation.

\section{Conclusion:}

In summary, the practical teaching in college dance teaching plays an irreplaceable role in the improvement of college students' professional skills. This is an important part of the college art teaching system in cultivating high-quality dance talents. Only active exploration in teaching practice links is constantly innovated. Expanding the channels of practice can effectively improve the level of dance education in colleges and universities.

\section{References:}

[1] Zhang Tingyu. Cultivating Middle School Students' Career in Dance Teaching Practice [J]. Literature and Art Life, Late 20th issue, 2018, (2): 214. 
[2] Zhou Zhihui. Exploration of dance education reform in colleges and universities under the concept of creative education-Comment on "The Dance of Wushu Dance: A Preliminary Study on Dance and Dance Education" [J]. Contemporary Education Science, 2017, (3): Feng 3. 